\title{
Geopolitical diversity in Occupational and Organisational Psychology: shaking off historical comforts and confronting real-world challenges
}

\author{
Bill Buenar Puplampu and Chris Lewis
}

Abstract: This article explores the limited and myopic theoretical and research resource base of Occupational and Organisational Psychology (OOP), a field which is a major contributor to global management thinking and practice. As a field, OOP has tackled many work-related human challenges. Considerable progress in both theory and practice in nearly 120 years of active engagement with society has led to theories of work, motivation, selection, performance, organisational behaviour, and development. Much of OOP work now informs and interfaces various Human Resource and general management initiatives. These advances notwithstanding, we note a major gap: the lack of diversity in the geopolitical and international sources of OOP theory. This article argues that to migrate theory and research into impactful practice - globallyOOP must engage a deliberate process of fostering alternative, autochthonous, and indigenous knowledge from geopolitical areas which are under-represented. The article proposes corrective actions and agendas which would assist OOP become more diverse and support the growth of Africa's contribution to global knowledge production in the work and organisational sciences.

Keywords: Geopolitical, diversity, Occupational and Organisational Psychology, Africa.

(C) The author(s) 2021. This is an open access article licensed under a

Creative Commons Attribution-NonCommercial-NoDerivs 4.0 Unported License 


\section{Introduction}

The body of knowledge of Occupational and Organisational Psychology (OOP) has enabled the profession to tackle many work-related human challenges across issues such as well-being, leadership, motivation, assessment, performance, work design, organisational change, and development. Considerable progress has been made in research, theory, and practice in nearly 120 years of active engagement with society. Apart from direct psychological interventions, OOP now informs and interfaces various Human Resource and general management initiatives.

These advances, notwithstanding, we note a major gap: the lack of diversity in the geopolitical and international sources of OOP theory. This article argues that to migrate theory and research into impactful practice — globally_OOP must engage a deliberate process of fostering alternative, autochthonous, and indigenous knowledge from geopolitical areas which are under-represented.

Specifically, to improve Africa's contribution to global knowledge production in the management and organisational sciences, a field such as Occupational and Organisational Psychology must deliberately foster a more inclusive sourcing of research and theory, as well as practice information from various African countries. We argue the need for an intentional agenda towards what we call geopolitical diversity (GPD) in OOP. We challenge the historical position that theories of work and organisation developed in the Global North must be applicable to the Global South. We challenge the notion that the current body of knowledge is a 'true' representation of the work and organisational experiences of humanity. We challenge the mindset which presumes that Africa's knowledge so mined, must necessarily be subject to the validation of Northern metropolitan scholars. We challenge the received wisdom, that OOP theory and research — as is - has been 'scientifically' derived. We raise issues with types of samples, research methods, lack of attention to meaning, and lack of attention to the globally diverse philosophies underpinning peoples' work lives. We take issue with the context-stripping that has characterised the pursuit of 'scientific respectability' in OOP.

\section{Under-representation of the Global South}

A matter of concern to those occupational and organisational psychologists who work outside the Global North is the rather poor attention to the development of OOP theory beyond the dominant postulations derived from the UK/Western Europe and the USA. There seems to be an assumption that OOP theories should sit and travel well, context notwithstanding. This is a patronising interpretation of 
organisational reality which has been queried by Trompenaars (1993), Fletcher (2009), Nkomo (2011), and others.

Drawing on the drive for indigenisation of management thinking and the growing concern for context (Johns 2006), challenges with OOP research and theorising (Anderson et al. 2001), as well as ongoing scholarly work in different African countries, this article makes the case that OOP would benefit from drawing in a more diversified field of research from other locations, such as South America, Africa, and Asia. We suggest that continued neglect and under-representation of such geopolitical areas of the world undermine the prospect of a truly global OOP. With reference to Africa which has some fifty-five countries, more than 1.2 billion people and much prospect for socio-economic transformation, it seems a globally inclusive OOP which draws in Afrocentric understandings, would be better placed to assist policymakers, researchers, and practitioners to tackle the organisational and work issues which abound. How may this matter be addressed?

We argue that the solution lies in methodological reflexivity, multi-perspective inclusiveness, as well as a deliberate and sustained promotion of efforts to mine work-related understandings from an autochthonous and indigenous perspective from countries in Africa and other parts of the Global South.

For example, work motivation theory explores the initiation, maintenance, and qualitative direction of work behaviour and has key principles such as the intrinsicextrinsic and drive-process divides. Despite evidence of varied approaches to motivation (Latham 2007), there is hardly any build-up of understandings from non-Western areas (Munro 1986; Puplampu 2013). In many of these places, the driveprocess and intrinsic-extrinsic divides appear tenuous and artificial (Puplampu 2017). Meanwhile these are the geopolitical regions with many concerns around productivity and work performance. Must occupational psychology interventions necessarily occur in the theory testing and externally derived mode? We argue not.

Leadership theory has grown considerably. In 2011, the (British) Journal of Occupational and Organizational Psychology (JOOP) attempted to explore leadership in Africa. Muchiri's (2011) paper shows the need to factor context into how leadership operates and Nkomo and Kriek (2011) conclude a set of grounded realities which are required of corporate leadership in the new South Africa. Puplampu's (2010) work in Ghana, indicates the impact of larger political considerations in the minds of institutional leaders and suggests how engaged leaders may build structures that outlive themselves. These scholarly efforts suggest that there is considerable scope for new indigenous learnings on corporate leadership in Africa and point to the potential for such to inform the global discourses on leadership. 


\section{The essential argument}

The position advanced by this article is that occupational and organisational psychology needs to enter a phase in which there is deliberate effort to mine alternative, varied, and diverse understandings from further afield - beyond what mainstream OOP theory is used to. The question may be asked: how much testing has already taken place to ascertain the applicability of extant theory to different locations? The counter argument is that knowledge generation in under-represented locations may proceed with or without the testing of existing (nonlocal) theory. Indigenous and autochthonous forms may be accessed for their value and potential contribution.

Real-world problems and challenges of poverty, modernity juxtaposed with tradition, disease, information asymmetry, discontinuous development, institutional weaknesses, 'produced resource' poverty amid 'natural resource' wealth; these are the issues in African countries and other parts of the Global South. There are cultural issues, economic opportunities, social stagnation; political, institutional, and Statelevel weaknesses; thriving traditions and norms, and the considerable influence of religion (Nkomo et al. 2015). Africa and the Global South can contribute to truly internationalising OOP by providing context-rich evidence. We argue that relevant theory and research that is impactful on practice must draw in location-specific knowledge. Location-specific and autochthonous knowledge needs to feed into the development of indigenous theory. In an increasingly globalised international space, conceptual relevance, rigorous research, and impactful practice cannot be attained without deliberate attention to varied and locally mined knowledge. This is what we mean by geopolitical diversity in research and theory.

\section{Geopolitical diversity}

Geopolitics is an 'old' field which perhaps came into its own with the cold war. It represents the reality of multiple nation states and the unequal and varied political power relations between and among countries in the context of their international relations. These differential powers are often concomitant to and consistent with military might, trade, economic development, and, lately, regional alliances.

Diversity in psychology refers to the understanding that people differ in their abilities, values, personality, and dispositions (Mollerman 2005). In OOP, much is made of workplace diversity as a key resource which offers the organisation a range or pool of abilities, experiences, opinions, talents, skills, and strategic cognitions (Ely \& Thomas 2001). In cultural studies, diversity underscores the recognition of multiple histories, traditions, cultures, cultural goods/services, meanings, peoples/ races, religious options, and societies (Harris \& Moran, 1996). 
Combining the three perspectives (international power dynamics, socio-cultural dynamics, and individual dynamics) we submit that geopolitical diversity (GPD) in OPP is the quality of recognising firstly that the power structures within our science are varied and uneven and many nations and regions of the world are not as represented in the science as may be ideal. Second, that there is no mono-cultural experience by which to assert a universality of theoretical propositions. Varied cultural contexts, histories, and experiences are therefore legitimate for research and theorising. Third, commitment to both researcher reflexivity and the lived voice of the researched (Johnson \& Cassell 2001) are important and critical to developing an OOP that is globally connected and locally relevant. In sum, GPD in OOP is a call for methodological inventiveness and theoretical comprehensiveness derived from geographic inclusiveness. It is a call to shed historic comforts and get involved with the real-world work challenges of more than $75 \%$ of the earth's population.

In the rest of the article, we tackle the history and impact of OOP and its historical dogmas and comforts. We tackle the challenges of the Global South in general and the concerns of Africa in particular - with a focus on management and organisational issues. We then set out the needed changes within OOP from the theoretical and gatekeeping as well as research methodological perspectives. We offer a corrective agenda as well as a consideration of how OOP scholars in different African countries may claim or reclaim the imperatives required to infuse mainstream OOP with learnings from the African context.

\section{Occupational and Organisational Psychology: what is it, and how is it doing?}

The use of the discipline of psychology to help understand the relationship between people and work has about a 120-year history - developing most of that time from the United States, Europe, and Australia. Different terms are used to describe this applied discipline including: 'work', 'industrial', 'organisational', 'occupational, 'and 'business' psychology - depending on which of the geographical areas the development has come from. For the purposes of this article, the title 'Occupational and Organisational Psychology' (OOP) will be used. There are other applied area descriptions that are sometimes seen as overlapping OOP by those wishing to understand the psychological aspects of work. These include: Industrial Sociology, Behavioural Science, Behavioural Economics, and Management Science. The nature of the distinction is outside the discussion of this article.

The historical development of OOP has broadly been to move from focussing on a psycho-physiological paradigm, to a social process paradigm; then an 
organisational process paradigm, and more recently an affective process paradigm, but all of these are still of interest (Kwiatkowski et al. 2006, Carpintero 2017).

The applied domains of OOP can be presented in many ways. An illustrative list might be: job analysis, work motivation, individual differences including psychometric testing, employee selection, performance management, training and development, working with technology, organisational development and change, team building, leadership, and stress and well-being.

OOP, especially from its American and European roots, has tended to emphasise a scientific basis for understanding people at work. Therefore, in experimental terms, it has treated both people and work as either the Independent Variable (IV) or the Dependent Variable (DV). That is, seeking how you change the people component to fit into work, or how you change the work component to fit with people.

Over its history, OOP has grown in influence. It is widely taught, normally at a postgraduate level, across higher education sectors, and has led to the creation of professional and scientific associations to regulate standards in most of the 'founding' countries. It has strongly influenced management practices, especially in Human Resources and played a significant role in government policymaking. In the United States it was ranked as the 'fastest growing occupation over the next decade' (US Bureau of Labour Statistics 2014).

\section{Challenges within OOP}

Whilst its roots in the historically more industrialised parts of the world have caused the issues raised in this article, these have been exacerbated by some shortcomings in the development of OOP itself. Psychology, its underpinning discipline, for reasons given below, consists almost entirely of 'arbitrary' metrics (Blanton \& Jaccard 2006) and relies totally on the observation and measurement of behaviour to achieve its scientific goals. Any attempt to claim the identification of innate psychological constructs is easily challengeable.

OOP began experimentation by observing behaviour change produced by different situations or conditions. For example, did productivity improve by altering work patterns? Here behaviour was used as the DV. Later, behaviour (in the form of how subjects responded to tests or questionnaires) was and is used to identify levels of cognitive or affective traits. Here the behaviour is the IV. More recently, research into areas such as consumer behaviour by 'behavioural psychologists' has utilised behaviour change as the DV.

The distinction is important. When using behaviour as an IV, the judgement about the relationship between innate psychology and behaviour must be made at the beginning of the experimental procedure, whereas when used as the DV it is made at 
the end. The relationship is difficult and highly subjective and different between the two situations. All innate psychological constructs have to be considered as non-ratio scales (there is no observable zero point) (Blanton \& Jaccard 2006), whereas behavioural measures are ratio scales with known scale qualities. Thus, behaviour and innate psychology are inevitably different metrics that are only comparable in a largely illusory way. This renders any meaning subject to bias, including cultural bias.

Thus, GPD might not be just a matter of research exclusion but one of inherent problems in OOP itself. Any applied psychology discipline requires quite a large conceptual leap from the base discipline to its applications, especially if such applications take place outside of the initial context of the development of base theory or construct. Another major problem is the development of OOP as a 'scientific' research-based discipline, which has tried to search, rather naively, for 'laws' of work behaviour. A classic example being the 'landmark' Hawthorne Studies (Roethlisberger \& Dickson 1939), recently discredited (Mannevuo 2018), which suggested that human relations, rather than physical conditions, will increase productivity. This was, for many years, accepted as a generalisable finding.

The problem has been that most experimental studies in OOP are context dependant. They are conducted, for example, in a particular business sector or industry, or even a particular office or factory. Whilst sometimes the context is controlled and becomes the IV, more usually OOP research relies heavily on serendipity. One may argue that these are 'case studies' with little or no external legitimacy. There can only be real generalisability if there is successful replication across other contexts. Thus, those seeking to utilise the conventional 'scientific method' are faced with having no control over the origins of the data from which conclusions can be drawn. This can produce errors in identifying research objectives together with random, systematic, or exclusion errors (Jones-Rooy 2019). So much of OOP research does not lend itself to generalisation and therefore cannot be universally applied. This issue is very much at the heart of this article.

As a result of the above, a methodological battle has raged within the discipline. The 'scientific' purists hold on to a belief that a positivist approach will always count for more, whilst some argue that using evidence of what has naturally been found is no less empirical and is the essence of OOP (a point discussed later in this article). It has caused, for quite some time, a noticeable divide between those academics and practitioners who prefer quantitative methods and those who mostly adhere to qualitative approaches (Pratt \& Banaccio 2016). Thus, much OOP research often falls between 'two stools'; with many using quantitative methods and failing to see such work really as 'case studies'. Not only has the outcome limited generalisability but has limited the learning from the process. OOP must learn that usually the only thing that is generalisable is that its work is not usually generalisable. It must develop a way to 
accommodate this. If this is achieved, the impact of OOP will continue to grow and be recognised for its universal value.

\section{Confronting historical dogmas: is it blatant myopia?}

As mentioned above, so much research in OOP lacks external validity. That is, it lacks evidence that findings in whole or in part can be validly applied to any other situation than is present in a particular research design. This is partly due to the difficulties of research and theory building in the applied social sciences in general and some specifics in OOP that have been discussed.

\section{WEIRD samples}

Whether it is because academics have been under pressure to publish research to further their careers and therefore been attracted to quicker and easier research projects, a phenomenon has existed for many years that shows little sign of abating (Pollet \& Saxton 2019). This is that research samples are dominated by subjects from Western, educated, industrialised, rich, and democratic (WEIRD) cultures (Henrich et al. 2010). These are the characteristics of America, Europe, and Australia where OOP has been developed, a geographical area often referred to as the 'Global North'. Therefore, these samples, that are conveniently local, are WEIRD samples. Even more so if they are students or business organisations well known to the researcher. Examples of the country sources of samples for much relevant research can be noted by examining the content of highly regarded journals in the applied social sciences (including outlets for OOP research). The evidence is suggestive: USA 68\%; UK, Europe, Canada, Australia, and New Zealand 27\%. Thus, the WEIRD cultures had $95 \%$ of the sampling balance. The rest of the world had 5\%, with Africa having the lowest representation (Arnett 2008). Another study also reported that $68 \%$ of samples were from the United States, with 'The West' accounting for over $90 \%$ (Henrich et al. 2010). More recently (Pollet \& Saxton 2019) reported 81\% of samples as 'Western', with only $6 \%$ of the remaining samples being from African countries. They also observed that $70 \%$ were either student samples or sourced online. The scholars referred to above were clear to point out why WEIRD samples will not contribute to the global knowledge of a social science field. Arnett listed markets, religion, community size, and the evolution of fairness and punishment as particular issues that might not be accommodated by using WEIRD samples. Henrich et al. identified reasoning style, conception of self, and importance of choice and notion of fairness as the issues. 
From a global point of view, WEIRD sampling is seriously harming the integrity of OOP, but it does not appear to be going away.

Worryingly, a solution to the problem is seen, by some researchers, to be the use of very large samples via the internet. Whilst supporting this notion, Jones (2010) offers caution that this might be moving from WEIRD to 'wired' people. The use of big samples be it by the internet or the retrospective use of 'Big Data' will remove some bias by being more inclusive, but this is likely to include 'racial' groups as perceived by the researchers. They are likely to miss the key issues of 'culture' and 'ethnicity'. The benefit of large sample research to most researchers is that it reduces 'error variance' across the sample, which removes the effect of the bias across the sample (Lewis \& Drye 2018). In this case, it removes the influence of any cultural effect - a classic case of context stripping. This is the very opposite of what GPD is trying to achieve.

\section{Confronting historical dogmas: the context concerns of the Global South}

The 'Global South' is a descriptive term typically used by donor agencies and multilateral agencies such as the World Bank. The term emerged as an alternative less pejorative handle to reference the countries of Central/South America, Caribbean, Africa, Asia, and the Middle East. Carl Oglesby (1969) is credited with earliest use of the term. These countries account for a little over 5.5 billion of the world's population, the vast majority of the world's natural resources, but approximately $5 \%$ or less of global trade and high finance. Until 2009, when the global financial crises forced a review - and subsequent creation of the G20 at the level of heads of state-Global South countries were hardly consulted on global economy issues (Kaul 2013).

Historically, nearly every country in the Global South has experienced colonisation by a Northern metropolitan power. Some countries have experienced severe trauma meted out to their indigenous peoples (for example, Belgian Congo). Others have suffered the indignity of resource dispossession through inward migration which has favoured peoples of the Global North (for example, South Africa). In terms of living standards and social experience, poverty is endemic and there are wide income/wealth disparities within countries. Another key marker is weak physical infrastructure such as roads and telecommunications. However, there are wide differences. Countries such as those described as the BRICS (Brazil, India, China, and South Africa) have made considerable progress in road, rail, and telecoms. Countries such as Kenya have led the world in the use of mobile telephony for banking services; countries like Ghana have now been described as middle income.

Socio-culturally many countries categorised as part of the Global South have grappled with internationalisation that has 'eliminated' borders and exposed 
traditional ways of life to compete and coexist with Western and globalised society and social arrangements.

\section{Africa}

For the purposes of this article, a bit more attention will be focused on Africa. The continent is not an undifferentiated whole. It is made up of fifty-five countries; distinct geographic regions; and eight regional economic blocks recognised by the African Union. These are: Arab Maghreb Union (AMU); Economic Community of West African States (ECOWAS); Common Market of Eastern and Southern Africa (COMESA); Community of Sahel-Saharan States (CEN-SAD); East African Community (EAC); Economic Community of Central African States (ECCAS); Intergovernmental Authority on Development (IGAD); and Southern African Development Community (SADC).

Arnold (2005: 970) in a significant work on Africa's modern history traces the independence struggles and concludes:

Africa has little influence and less power, a fact that attracts the major powers like vultures to a carcass to be exploited. If there is to be an African renaissance it will be achieved by the skillful deployment of what Africa itself controls.

Reader (1998) in an influential book on the history of the continent, demonstrates humanity's debt to Africa as the cradle of sapiens' evolution. The challenges of the continent are perhaps best captured by Knight $(2011: 5 ; 681)$ who describes the struggle of indigenous Southern Africans with a focus on the Zulus uprisings in the late 1800s as they sought to dislodge the entrenched white settlers. He writes with poignant pathos:

The invasion was, moreover, part of a broader process of colonial penetration of Zululand which began with the arrival of the first white adventures ... lasted for the best part of a century ... and which left the Zulu people dispossessed.

The defeated lost not only the lives of thousands ... but also their independence and the very fabric of their way of life.

In recent times, many scholars in the field of management have described some of the challenges of the African continent. Nkomo (2011) writes about the colonial legacy and its imprint on characterisations and non-characterisations of leadership examples in Africa. Lituchy et al. (2013: 2) note that:

Its relationships with the world external have been so commoditised that it seems wherever Africa is discussed, the discussion turns to its resources. 
Given the range of issues identified about Africa and the Global South, what are the specific problematics and issues in these geopolitical areas which are poorly handled by current OOP? We identify four major areas.

\section{National political dimensions of in-firm experiences}

Work by Munene (1995), Nkomo and Kriek (2011), and Puplampu (2010, 2017) shows that in the varied country contexts of Africa, managers and executives cannot overlook the national political imperatives which have an existential reality for their firms. Nkomo and Kriek (2011) find that organisational leaders in post-apartheid South Africa needed to connect with the larger political changes in the country and bend their leadership efforts towards offering hope and championing diversity. Both these themes have direct organisational as well as larger political/socio-economic character derived from the politics of the country. Similarly, Puplampu's work in Ghana found many organisational processes subjected to the incursions of national political actors.

A simple reading of over 100 article titles and abstracts (akin to the approach used by Pisani, 2009) constituting the papers published in the Journal of Occupational and Organizational Psychology (JOOP) over a five-year period (2015-19; Vols. 88-92), shows that very few of the abstracts contain words such as: 'politics', 'country', or 'national development'. Those that did tended to be papers described as 'crosscultural'. There are perhaps several interpretations of such a situation. Two such interpretations may be that those considerations did not arise in the case of the articles considered, or, location notwithstanding, editors did not require such information to label the context of the research reported.

\section{Size of the informal sector}

The informal sector of socio-economic life is huge in many African countries. Medina et al. (2016) indicate that the informal economy operates outside of the administrative rules, licensing contracts, and general legal control. They conclude that as much as $65 \%$ of economic activity takes place within this sector. Activities here would include operators of kiosks, table-top sellers, sole proprietors, transport owners, motorcycle taxis, and food vendors who take orders from home, cook at home, and deliver to clients from home etc. Add to this the SME (small and medium-sized enterprise) sector which is suggested to be $95 \%$ of business firms in sub-Saharan Africa (Ndiaye 2017). The implication here is: given the organisational and business sampling used in much of OOP research, how relevant would the prescriptions be? 


\section{Environmental constraints on the effort-performance hypothesis}

Much of the received wisdom in organisational behavior is that guided individual effort can lead to enhanced performance. Crucial factors here include self-efficacy, environmental control, and job resources. These are at the core of goal setting theory (Latham 2007). The difficulty for application to many areas in Africa is that there are such a wide range of environmental contingencies over which workers often have little or no control. Take information asymmetry; power outage and lack of consistency in provision of utilities; poor national physical infrastructures, and still developing legal frameworks.

\section{Context: macro issues and religious sensibilities}

The above points all have a bearing on the issue of context. Writing on employee motivation in the African setting, Puplampu (2017) notes that contextual factors on employee motivation include: socio-political history, national economic circumstances, spirituality, and religion.

Context is both a subtle as well as an overt reality which needs to be recognised for its complexity. Johns (2006: 386) has offered a seminal treatment of the issue. $\mathrm{He}$ defines context as:

Situational opportunities and constraints that affect the occurrence and meaning of organisational behavior as well as functional relationships between variables.

Johns indicates that context operates at two levels: the omnibus (larger milieu and atmosphere) and the discrete (specific variables directly impinging on behaviour), each exerting nuanced influence on phenomena. He also offers a six-point taxonomy of context as: salience, situational strength, cross-level effect, an event, shaper of meaning, and as a constant. Johns' (2006: 389) analyses suggest that researchers need to regularly design context influences into their work: 'The point being made here is not that context is never studied. Rather it is that its influence is often unrecognized or unappreciated' (emphasis Johns'). Why is all this relevant for OOP research and theory?

\section{Historical comforts}

First, in the last two or three decades, there has been increasing disquiet within the field about resource myopia (Drenth \& Heller 2004) and the narrow range of organisations from which OOP derives its samples and among which research is carried (Patterson 2001). There is also concern about 'weak science' leading to populist, 
puerile, and pedantic research efforts (Anderson et al. 2001). There is also some disquiet about the issues OOP research has focused on and successive editors of the leading scholarly journal the $J O O P$ have called for greater attention to meaning, lived experience, philosophical underpinnings of peoples' work life, and so on (West et al. 1992, Sparrow 1999, Arnold 2004). These concerns speak to both omnibus and discrete context.

Second, the dominant position of much of OOP scholarly output, seems to be that rich and/or applicable description of the context may not be required. Third, both research and theorising seem to assume that scholarly prescriptions are applicable irrespective of location, meanings, and underlying social and/or organisational philosophies. An example of this may be found by looking at the Tadic et al. (2015) paper in the JOOP. The research was about primary school teachers in Croatia. The paper offered no description about Croatia or the lives of primary school teachers in that country; nor did it touch on why - if at all — the issue/s of job demands/wellbeing/job resources were critical for study (at the time, with that group or that sector in Croatia). In setting out the 'practitioner point' bullets (which is now a requirement for publishing in the $J O O P$ ) the authors made no qualifications as to the applicability of the findings or suggestions or points within or outside Croatia. The writers, however, did indicate the need to replicate the work in other 'work settings' (720). This is not meant as a criticism of the work. It is simply a reflection of the context poverty we speak of. Is the lack of context detail a result of journal policy, the assumptions of the authors, an unquestioned normative position, or blatant myopia as we noted earlier?

This is, perhaps, the heart of the historical comforts that OOP has allowed itself to enjoy. Research and theory seem to assume context and universality of application. OOP seems to assume rigour is dependent on replication through sophisticated quantitative means. OOP ignores other world regions and hardly tackles the 'global', 'national', and 'cultural'. The field appears non-cognisant or unconcerned about the potential reach of its theoretical formulations; a potential reach which calls for greater regard and inclusion of 'otherness' (Hegarty 2019: 48). The historical comforts may have become so ingrained that Hegarty's description may be symptomatic: 'People cannot always access the assumption they have made which is limiting their thinking.' Never mind that these 'people' are psychologists!

The net result is that OOP is shorn of potentially valuable contributions from other regions meanings, philosophies, and communities. We now consider how the field appears to 'conspire' to keep out the 'other'. 


\section{GPD in Occupational and Organisational Psychology: confronting dominant theory and gatekeeping}

There are two obstacles facing GPD of OOP that are related to the phenomenon of 'knowledge'. The first is about its quality; the second about its communication.

\section{Theory challenges}

GPD needs benchmarks to judge its effectiveness. These would normally be solid theory, an attribute that has been said is noticeably lacking in OOP, as stated by Herriot \& Anderson (1997: 13):

No other sub-discipline in the organisational sciences has exhibited such a paucity of theoretical perspectives ... if the discipline fails to stimulate a diversity of theoretical perspectives and epistemological approaches, it runs the risk of becoming an overheated engine house of remote, blind, empiricism.

It has been argued that this problem has been aggravated by researchers in the field of psychology (therefore by implication OOP), failing to acknowledge the assumptions and preconceptions they bring into research. That is failing to clearly recognise the distinction between justified belief and opinion (Johnson \& Cassell 2010). This is worsened by OOP researchers who are sometimes guilty of attempting to develop theory with the sole purpose of prediction, making assumptions about what they are measuring and the validity of the prediction, when these are both-according to Lewis \& Drye (2018)—largely illusions.

To be fair to OOP, perhaps many attempts to build theories get quickly overtaken by the need to demonstrate practical application. The very nature of the field is to create tools that benefit an efficient relationship between people and work; in practice that often means devices that enhance business and/or management performance. There is a business 'bottom line' issue here. Theories are developed into management 'techniques', with application treated (perhaps inadvertently) as a form of replication or test of the original research work. Theories become a feature of the original methodology. Eventually the applications fail as replications and the lack of generalisability shows through (Tourish 2019). The theory starts to be seen as a 'fad' and its use declines. This lack of sustainable theory is a problem for OOP.

By way of example, the 'Two-factor Theory of Motivation' (Hertzberg 1966) had a huge impact on research and practice in 'motivation at work' during the second half of the last century, but as has been pointed out (Hertel \& Wittchen 2008) the theory could not be replicated using other methods (King 1970) and can be explained by attribution theory (Weiner 1986). Far less is heard of the theory now. 
Another, more recent, example is 'Engagement Theory' that identifies the performance benefits of personal engagement of individuals with their work (Kahn 1990). This is reported to now be in decline (Briner 2014). This is alleged to be so because its application is made difficult as the basic assumptions are 'normative' and 'aspirational' rather than 'analytic and operational' (Keenoy 2013).

Theory building in OOP, therefore, has challenges - not helped by the tendency for theories, after initial publication, to be syphoned off to serve as new management practices. In furtherance of GPD, maybe what OOP needs is not devalued 'established' theories but 'theoretical suggestions' that can be hypothesised and tested using more local methodological designs.

\section{Communicating non-western formulations in western outlets}

The second obstacle is that which constrains GPD academic output from penetrating the Global North home of OOP. This is about getting research in the field published. Research needs to appear in academic journals. Research in supposedly prestigious outlets is treated with greater reverence and impact - relevance and inherent quality notwithstanding (Singh et al. 2007). Without this, it is believed, the value of the research will not get the recognition it may deserve. But 'prestige' is driven by several factors. The first is that 'prestigious' journals in the field are almost exclusively found in the Global North, fuelled by research audit exercises used to judge the performance of universities, departments, and individual researchers. The second is that they operate in a highly competitive hierarchy and, third, they tend to publish in the English language.

Historically, journals have tended to look inwards to the research practices of their own region. This has made it difficult for academics in the Global South to break in. Indeed, any focus outside has often been presented as a 'special edition' of the journal. This has meant that Global South researchers often feel that they must fit into what they see as a Global North methodological template. Tourish (2019) refers to the work of Bell et al. (2017) that management studies researchers in India are put under pressure to use positivist and quantitative methods to have the chance of publishing in American journals.

Inter-journal competitiveness is a problem. Prestige is often seen to be related to rejection rate. The harder it is to get a paper published the more highly some will regard the journal as it publishes only the 'best'. They offer the number of citations over a two-year period (the Impact Factor) to support this claim. However, this may not be a valid test as over a two-year period $90 \%$ of papers are not cited at all, and $84 \%$ are not cited over a five-year period (Alversson et al. 2017). Further, Pidd and Broadbent (2015) set out to find how the prestige rating of business and management 
journals compared with the ratings that these same papers achieved in the 2014 UK Research Excellence Framework (REF). They found a huge variation between the two. Many papers accepted by prestigious journals were poorly rated by the REF, and 'vice versa'. It should be noted, however, that the REF itself has been criticised for applying narrow traditional criteria in assessing academic worth (Sayer 2014, Tourish 2019). If this criticism is valid, it indicates a further bias against scholars from the Global South.

Add to this the traditional reviewing system which has recently been described as full of bias with reviewers approaching their task 'through the lens of criticism' (King et al. 2018, Tourish 2019). This is an obstacle that is largely self-explanatory.

The final obstacle is one of language. Any academic wishing to publish in an English-language journal whose first language is not English knows they have to deal with the issue: get their paper 'translated'. However, in the Global South this is not quite so straightforward. Ghana is a good example. Its official language is English and most people who have gone through the education system speak it. However, the country has over twenty other recognised languages based on tribal heritage. For most, this will be their first language. Thus, many researchers in Ghana and elsewhere in the Global South where a similar situation exists, will be confident that they can write a journal paper in English, but may produce a formal style that is unfamiliar to a journal reviewer, and thus affect the chances of the paper being accepted. Here is a problem of how a lack of GPD impinges on language use and how language impinges on GDP. This issue has to be resolved.

\section{GPD in Occupational and Organisational Psychology: confronting method reflexivity}

For much of its history, Occupational and Organisational Psychology has struggled with tensions between its philosophical base in the human experience of work and its efforts to gain scientific respectability. To gain respectability, OOP has pursued methods which enable it to demonstrate commitment to rigour, replication, and reliability — often, this has meant a positivist and quantitative emphasis. This tension, discussed above, has not been resolved. It has, however, produced much by way of debates, concerns, and calls for pause which have been variously referred to in this article.

Several conclusions may be drawn from the methodological progress of OOP and from the debates in the literature. These include the following: 
1. OOP methods have been overwhelmingly positivist.

2. Much use is made of sophisticated tools such as statistical meta-analyses and structural equation modeling.

3. Scholars have noted the drive for identifying or concluding causal relationships among variables to the neglect or consequential elimination of context.

4. Whilst much progress has been made, the positivist stance has perhaps inadvertently led to much atheoretical scholarship as well as less focus on 'real-world' problems.

We criticise the consequent exclusion that inflexibility facilitates. In a special issue on 'Work Motivation', the journal Applied Psychology: An International Review (Vol. 49 No. 3) of the year 2000, seventeen papers and an editorial were published. None touch on work motivation from Global South or African domains. The issue was described as a 'Special Issue on Work Motivation: Theory, Research and Practice'. In the Centenary Issue (2001) of the Journal of Occupational and Organizational Psychology (Vol. 74 Part 4), described as 'Emerging issues and future trends in OOP', there were eight papers, an editorial, a summary, and a concluding piece. None of these touched on this key OOP area from alternative locations.

Is this because not much OOP research takes place in these alternative locations? We think not. We posit that this is the direct result of exclusion arising from methodological foci and a lack of an internal diversity ethic. Interestingly, for a special issue of the JOOP (2013, Vol. 86 Part 2) described as 'Getting Diversity at work to work' the focus of the eight papers was on diversity management issues within organisations without alerting the science of OOP to the reality that to appreciate diversity in practice and to inform it, researchers need to appreciate the diverse and deep contexts from which the members of an organisation may come.

\section{Reflexivity required}

Patterson (2001: 383), echoed without so saying, the urgent need for OOP scholars to recognise and become more reflexive of research and theorising.

Researchers must be wary that a great deal of the research literature reported in journals is derived from the private sector blue chip corporations ... this may distort reality. ... Rousseau and Fried ... criticized the lack of reporting of the organisational context ...

There is a paradox here. High reflexivity suggests a greater effort to frame issues because of how one sees those issues. This could lead to insularity. However, the nature of reflexivity needed at this time, is suggested by Johnson \& Cassell (2001: 127): 
Perhaps the most we can hope for ... is to become more consciously reflexive by thinking about our own thinking, by noticing and criticizing our own epistemological pre-understanding and their effects on research.

With specific reference to GPD in OOP and inclusion of Afrocentric thought, OOP needs to pause and reflect on how its epistemes and inherent teleology conspire to prevent it from tackling those issues which affect the majority of the world's people and thus stop it from becoming truly global.

What is the way forward? Before exploring some thoughts as to the way forward, it is perhaps necessary to set out what the African context/s and the Global South context/s may provide to OOP.

\section{Why diversify? And why GPD?}

There are many 'reasons why' and there are many benefits that could accrue to OOP if it achieves GPD. We set out some of these below.

\section{Truly global}

Perhaps the most significant benefit that would accrue from a geopolitically diverse OOP, is that the field would finally become truly global and representative of the business of OOP in our world. Successive conferences of the British Psychological Society's Division of Occupational Psychology have had themes which suggest the need to tackle real-world problems. Themes have included: 'Resilience in a challenging world ...' (2016); 'Research into practice: Relevance and rigour ...' (2017); 'Evolution or Revolution? ...' (2018).

The challenging world 'out there' is $75 \%$ or more Africa and Global South. As it currently stands, OOP - deliberately or otherwise - is a field which demonstrates a colonial mindset. The colonial mindset operates by assumption of right of dominance or preeminence derived from a de-legitimisation of the other and/or the indigenous. Nkomo (2011: 366) explores the 'hegemony of western conceptualisations' of management thinking and notes in a reflection of how deeply altering colonisation can be, that:

While my search revealed that Africa was all invisible in the mainstream leadership and management literature, I also found a body of literature that has risen in response to the exclusion and marginalisation of Africa in [the] ... discourse. Yet, these alternative representations often unwittingly preserve ... the ideological coding of Western (primarily US) conceptions ...

A truly diverse OOP can help to decolonise theory. 


\section{Theoretical re-imagining}

Data from non-Western areas would assist the reconsideration of many theoretical assumptions which currently guide OOP. Many social science fields have recognised and worked to include and reinvent their theories using data findings from many countries. This is perhaps one of the reasons why Economics as a social science is such a dominant force in developing areas. Its theorists do not shy away from researching and drawing in data from the remotest of locations.

\section{Relevance for practice}

African countries continuously spend considerable sums on consulting services aimed at institutional and organisational improvements. From leadership through motivation to organisational development, locally mined concepts which resonate with the history, experience, and traditionally deep-seated norms of the locale would more than likely facilitate better adoption and application of important OOP concepts.

\section{Contribution of indigenous knowledge to global knowledge}

A geopolitically diverse OOP would stimulate the inclusion of autochthonous and indigenous knowledge to the global conversations. This goes to the heart of the context demands made by Johns (2006). Referring to why Nkomo \& Kriek's (2011) submission won best paper, the then outgoing editor of the JOOP, Jan de Jonge (2013: 3) noted:

Their study shows that research on leading organisational change can really make a difference to policy ... leading ... change in societies that undergo this kind of fundamental restructuring is a huge challenge that has not yet been adequately addressed in the Western leadership and change literature.

The above quote along with the context concerns raised earlier, suggest that the time is right for OOP to interrogate itself and commit to a strategy of inclusion.

\section{The way forward towards GPD and Africa's inclusion within OOP}

In this section, we set out our thoughts and suggestions as to how OOP may drive an inclusive GPD programme. We offer a five-point agenda. 


\section{Research approaches and methods}

We suggest that OOP scholars should ask the question: what methods are best disposed to mine the realities of 'other' areas? What research approaches would facilitate sustained attention to and engagement with Global South OOP issues? Puplampu (2016) makes suggestions for management research which are applicable here. $\mathrm{He}$ suggests that use of Hermeneutics, Graphic Scales, and Applied Interventions as useful tools. These are rather specific. Perhaps more generally, a greater use of phenomenological approaches is called for.

We argue for a greater use of the Case Study Method (CS). The major case for the adoption of the CS is the acquisition of knowledge. Flyvbjerg (2006) usefully referred to the following view: 'Quantitative knowledge does not replace qualitative common sense. Qualitative knowing, with all its faults, is all we have. It is the only route to knowledge' (Campbell 1975: 179).

Thus, if knowledge cannot be generalised it does not mean it cannot enter the collective process of knowledge acquisition in a given field or society (Flyvbjerg 2006). It follows, therefore, that the use of geopolitically diverse case studies would enhance the generalisable understanding in the field of OOP. Case studies also work well as a test of 'falsification'. Karl Popper's much-cited view that you might theorise that 'all swans are white' until you came across one that is black is an example of one case being sufficient to negate a whole theory. This illustrates the relevance of the CSM, and its role in GPD.

Finally, it should be noted that case study methodology is not driven by the need to average the data and dismiss outliers. These having been described as probably the richest source of understanding (Lewis \& Drye 2018). It also provides exemplars and paradigm cases (Geertz 1995) and gets closer to the researched than quantitative research - allowing the correction of the process through ongoing feedback.

\section{Developing theories: theory sensing or theory suggestion?}

Scholarly theories are the product of world views domiciled within the milieu or context of the theorist. Theories may be speculative or may arise from attempts to bring analytical consistency to a social or human problem. Drawing on Colquitt and Zapata-Phelan (2007) and Whetten (1989) theoretical contributions must satisfy several important criteria. These include all-round $360^{\circ}$ consideration of matters that explain the variance in phenomena; hence answering the questions: What? How? Why? Who? Where? When?

For OOP to access these criteria, a consideration of autochthonous knowledge, indigenous knowledge, and grounded knowledge is necessary. Each of these address nuanced representations of lived reality. 
While notions of autochthonous reality suggest that the factor or variable originate from a location, allochthonous reality refers to elements that are imported into an ecosystem. Indigenous reality is often closely associated with the autochthonous, in that both refer to a level of nativity or originality which predates external invasion or colonisation by whatever means. The extent to which present-day human societies can lay claim to 'autochthonous-ness' is obviously a matter that may be subject to much romanticisation (Nkomo 2011). This issue is resolved by a commitment to grounded knowledge.

To attain GPD, OOP scholars need to work to develop theories that are grounded to the locale. In pursuing grounded theory (both as method and as philosophy), OOP scholars are likely to unearth nuanced distinctions between autochthonous and allochthonous realities. A country that would lend itself to such discovery would be South Africa. With a history of over 300 years of European presence (allochthonous) and over 30,000 years of Bantu/Khoisan presence (autochthonous), it would be interesting to understand what constitutes work motivation (or engagement or leadership) for the now indigenous population of both African and European descendants but who have been shaped by a difficult and differentiated history of conquest, exploitation, subversion, dominance, and apartheid. It is worth noting that the UN holds that indigenous people are effectively first nation people who were at a geolocation before settlers, colonisers, and vanquishers showed up (undated UN Factsheet). We specifically reject the suggestion, for example, that a theory developed in South Africa without these grounded and differentiated understandings would sufficiently capture 'an African reality'and by extension would sufficiently represent an 'African understanding'. GPD is a tough prospect.

Is there a place for theory testing? Colquitt and Zapata-Phelan (2007: 1298) suggest theory building and theory testing need not be viewed as a 'zero-sum' ideal. We agree. Yet we raise a caution. Theory testing by its nature, imposes a preexistent rubric. This preexistent rubric force and unwittingly enshrines a lack of epistemological reflexivity (Johnson \& Cassell, 2001). As indicated earlier in this article, a scathing comment was offered by Herriot and Anderson (1997) about this. This calls for what we describe as 'theory sensing and theory suggestion'. In other words, OOP should be aware that its propositions must carry an inherent recognition that our theoretical propositions are 'suggestions' and tentative based on emerging findings from 'somewhere' awaiting explorations 'elsewhere'.

These points of caution dispose us to call for a disruption of the theory testing received wisdom. In its place and in the interest of GPD, theoretical fecundity, and commitment to the voice of the locale, we suggest more OOP research in 'other' places should take place. Such research should proceed with a deep commitment to unearth 
locally grounded reality - even if such reality in the end is found to be consistent with already-existing suppositions.

\section{Journal access}

We think it is necessary for the scholarly journals which carry OOP research and theory to accept that both past editors as well as current scholars have been raising (and continue to raise) the issue of the focus and character of scholarly submissions. For GPD to work, scholarly journals must firstly accept the need to surface work from other areas such as African countries. Second, journals must consider the value that may be brought to the scholarly conversations from 'other' places. Third, journals need to work with scholars in such countries to better appreciate how to communicate to and with audiences for whom the locale and the indigenous may have no salience for their lives and professional execution. The gatekeepers need to keep the gate open a little more.

\section{The African proposition}

There is a resurgence within the African region, of its intellectual and knowledge capabilities. Various bodies and institutions have begun to mainstream an African agenda which is beyond the political and more related to the institutional and the intellectual. We speak here of initiatives such as the New Partnership for African Development (NEPAD); the African Union's Agenda 2063, and the renewed interest in the functioning of the various economic and regional blocks. In recent times, France is said to be releasing its stranglehold on the currencies of its old colonies and a West Africa Monetary Institute/Union is being seriously considered. Major Western Higher Education Institutions are setting up campuses in Egypt, Ghana, and other places. Various African countries offer the prospect of dual socio-economic reality (moderntraditional) as well as the full spectrum of micro, SME-large national and international corporates. There are real possibilities for OOP scholars to work with their African colleagues at universities and scholarly associations, with the intent of addressing the historical under-representation of psychological realities of African countries in the OOP international conversations. In 2015, the African Research Universities Alliance (ARUA) was set up with sixteen-member universities from nine countries - in like mode to the Russell Group in the UK; with the aim of enhancing the quality of research in Africa and executed by Africans to find solutions to development problems in Africa. We refer to ARUA to show that OOP scholars in the Global North can find OOP scholars in the Global South, with like-minded commitment to research and research quality. 


\section{The role of international psychological associations}

There are major scientific psychological associations in the West. These include the British Psychological Society (with its Division of Occupational Psychology); the International Association of Applied Psychology (with its Division of Organisational Psychology); the American Psychological Association (with its Division 14 - Society for Industrial and Organisational Psychology). The OOP divisions of these scholarly associations need to deliberately stir up from their historical comforts. The study of OOP and its application to the human condition in the 21 st century seems rather jaundiced when its greatest focus has been on the peoples and economies of the Global North who constitute approximately $11-15 \%$ of the global population of 7.8 billion.

Specifically, it seems reasonable to argue that the OOP associations should perhaps take a cue from the Academy of Management (AoM of the USA) which has in the last decade and half recognised the need to reach out and globalise the study of management. This has led to the setting up of regional affiliates, the holding of conferences in Africa and elsewhere, and a deliberate attempt to highlight African and other management issues by having relevant caucuses at each AoM annual conference. Specifically, these efforts have included direct engagement with scholars in African countries. OOP should adopt a similar strategy.

\section{Conclusion}

OOP has been far too comfortable with its presumed progress in tackling work issues. With progress comes responsibility. This responsibility-for OOP — should certainly include recognising that the application of OOP tenets (developed in the West) to other regions leaves several questions unanswered. Particularly that: as psychologists our interests should include studying, understanding, and applying tools of intervention to people, organisations, and economies based on in situ knowledge surfaced within the locale. The current situation where OOP theory and tools developed elsewhere are continuously applied in regions with different political, economic, social, historical, and philosophical traditions and contexts, seems rather un-psychological.

Research-to-Theory-to-Research-to-Practice is a continuum or cycle which must be informed by context-driven commitments (Johns 2006) not esoteric arguments of rigour and prescribed content based on externally derived notions of acceptability. Perhaps in the end, OOP should take a cue from the research of some of its own scholars and apply the diversity proposed for organisations to itself (Groggins \& Ryan 2013: 264): 'To promote a positive diversity climate, attend to structural inclusiveness.' This suggestion from OOP scholars is targeted at practitioners. We dare say, it is 
directly applicable to OOP itself. The suggestions advanced in this article would facilitate structural inclusiveness and geopolitical diversity of OOP. The question is, how ready and willing are Occupational and Organisational Psychologists to shake off historical comforts and bend their energies to the real-world problems that confront more than $80 \%$ of the global population? Human history suggests that inclusiveness and diversity is always a mindful and deliberate choice, hardly ever spontaneous.

\section{Acknowledgements}

This article was first delivered in a much-reduced form as a presentation at the British Psychological Society January 2017 Conference of the Division of Occupational Psychology in Liverpool, UK.

\section{References}

Alvesson, M., Gabriel, Y. \& Paulsen, R. (2017), Return to Meaning: A Social Science with Something to Say (Oxford, Oxford University Press). https://doi.org/10.1093/oso/9780198787099.001.0001

Anderson, N., Herriot, P. \& Hodgkinson. (2001), 'The Practitioner-Researcher Divide in Industrial, Work and Organisational (IWO) Psychology: Where Are We Now and Where Do We Go From Here?', Journal of Occupational and Organizational Psychology, 74(4): 391-412. https://doi.org/10.1348/096317901167451

Arnett, J.J. (2008), 'The Neglected 95\%: Why American Psychology Needs to Become Less American', American Psychologist, 63(7): 602-14. https://doi.org/10.1037/0003-066X.63.7.602

Arnold, G. (2005), Africa: A Modern History (London, Atlantic Books).

Arnold, J. (2004), 'Editorial', Journal of Occupational and Organizational Psychology, 77(1): 1-10. https://doi.org/10.1348/096317904322915883

Bell, E., Kothiyal, N. \& Willmott, H. (2017), 'Methodology-as-technique and the Meaning of Rigour in Globalized Management Research', British Journal of Management, 28(3): 534-50. https://doi.org/10.1111/1467-8551.12205

Blanton, H. \& Jaccard, J. (2006), 'Arbitrary Metrics in Psychology', American Psychologist, 61(1): 27-41. https://doi.org/10.1037/0003-066X.61.1.27

Briner, R. (2014), 'What is Employment Engagement and Does It Matter? An Evidence-based Approach to Employee Engagement' (Bath, University of Bath).

Campbell, D.T. (1975), 'Degrees of Freedom and the Case Study', Comparative Political Studies, 8(1): 178-91. https://doi.org/10.1177/001041407500800204

Carpintero, H. (2017), History of Organisational Psychology (Oxford Research Encyclopedias; Oxford, Oxford University Press). https://doi.org/10.1093/acrefore/9780190236557.013.39

Colquitt, J. \& Zapata-Phelan, C. (2007), 'Trends in Theory Building and Theory Testing: A Five-decade Study', Academy Of Management Journal, 50(6): 1281-303. https://doi.org/10.5465/amj.2007.28165855

de Jonge, J. (2013), 'Editorial-Time to Say Goodbye: Reflection on Four Years of Editorship', Journal of Occupational and Organizational Psychology, 86(1): 1-4. https://doi.org/10.1111/joop.12004 
Drenth, P. \& Heller, F. (2004), 'The Dangers of Resource Myopia in Work and Organisational Psychology: A Plea for Broadening and Integration', Applied Psychology: An International Review, 53(4): 599613. https://doi.org/10.1111/j.1464-0597.2004.00191.x

Ely, R. \& Thomas, D. (2001). 'Cultural Diversity at Work: The Effects of Diversity Perspectives on Work Group Processes and Outcomes', Administrative Science Quarterly, 46: 229-73. https://doi.org/10.2307/2667087

Fletcher, C. (2009), 'Commentary on the Inaugural Editorial of Management \& Organisation', Management \& Organisation - A Multidisciplinary Journal of Business, 1(1): 13-18.

Flyvbjerg, B. (2006), 'Five Misunderstandings about Case Study Research', Qualitative Inquiry, 12(2): 219-54. https://doi.org/10.1177/1077800405284363

Geertz, C. (1995), After the Fact: Two Countries, Four Decades, One Anthropologist (Cambridge, MA, Harvard University Press).

Groggins A. \& Ryan, A. (2013), 'Embracing Uniqueness: The Underpinnings of a Positive Climate for Diversity', Journal of Occupational and Organizational Psychology, 86(2): 264-82. https://doi.org/10.1111/joop.12008

Harris, P. \& Moran, R. (1996), Managing Cultural Differences (Houston, TX, Gulf Publishing Company). Hegarty, P. (2019), 'How Do We “Other”?', The Psychologist, May: 48-51.

Henrich, J., Heine, S. \& Norenzayan, A. (2010), 'The Weirdest People in the World', Behavioral Brain Science, 33(2): 61-83. https://doi.org/10.1017/S0140525X0999152X

Herriot, P. \& Anderson, N. (1997), 'Selecting for Change: How Will Personnel and Selection Psychology Survive?', in P. Herriot \& N. Anderson, (eds) International Handbook of Selection and Assessment (Chichester, Wiley).

Hertel, G. \& Wittchen, M. (2008), 'Work Motivation', in N. Chmiel (ed.) Introduction to Work and Organisational Psychology (Oxford, Blackwell).

Hertzberg, F. (1966), Work and the Nature of Man (Cleveland, OH, World Publishing).

Johns, G. (2006), 'The Essential Impact of Context on Organisational Behavior', Academy of Management Review, 31(2): 386-408. https://doi.org/10.5465/amr.2006.20208687

Johnson, P. \& Cassell, C., (2001), 'Epistemology and Occupational and Organisational Psychology: New Agendas', Journal of Occupational and Organizational Psychology, 74(2): 125-43.

Jones-Rooy, A. (2019), 'I'm a Data Scientist Who is Skeptical About Data', 24 September. https://doi.org/10.1348/096317901167280https://qz.com/1664575/is-data-legit/amp/?-twitter_ impression=true [Accessed 19 September 2019].

Jones, D. (2010), 'A WEIRD View of Human Nature Skews Psychologists' Studies', Science, 328 (June): 1627. https://doi.org/10.1126/science.328.5986.1627

Kahn, W. A. (1990), 'Psychological Conditions of Personal Engagement and Disengagement at Work', Academy of Management Journal, 33(4): 692-724. https://doi.org/10.5465/256287

Kaul, I. (2013). The Rise of the Global South: Implications for the Provisioning of Global Public Goods. (Occasional Paper 2013/08; New York, UNDP Human Development Report Office).

Keenoy, T. (2013), 'Engagement: A Murmuration of Objects?', in Truss, C. et al. (eds) Employee Engagement in Theory and Practice (London, Routledge).

King, E., Avery, D., Helb, M. \& Cortina, J. (2018), 'Systematic Subjectivity: How Subtle Biases Infect the Scholarship Review Process', Journal of Management, 44: 843-53. https://doi.org/10.1177/0149206317743553

King, N. (1970), 'Classification and Evaluation of the Two-factor Theory of Job Satisfaction', Psychological Bulletin, 74: 18-31. https://doi.org/10.1037/h0029444

Knight, I. (2011), Zulu Rising (London, Pan Books).

Kwiatkowski, R., Duncan, D. \& Shimmin, S. (2006), 'What Have We Forgotten and Why?' Journal of Occupational and Organizational Psychology, 79(2): 183-201.

https://doi.org/10.1348/096317905X70832 
Latham, G. (2007), Work Motivation. History, Theory, Research and Practice (Thousand Oaks, CA, Sage).

Lewis, C. \& Drye, T. (2018), 'When Illusions Become Assumptions is When Psychometrics Fails', OP Matters, The British Psychological Society, 38: 5-9.

Lituchy, T., Punnett, B.J. \& Puplampu, B. (eds) (2013), Management in Africa: Macro and Micro Perspectives (New York, Routledge). https://doi.org/10.4324/9780203111482

Mannevuo, M. (2018), 'The Riddle of Adaption: Revisiting the Hawthorne Studies', Sociological Review, 66: 1242-57. https://doi.org/10.1177/0038026118755603

Medina, L., Jonelis, A. \& Cangul, M. (2016), 'The Informal Economy in Sub-Saharan Africa: Size and Determinants' (IMF Working Paper WP/17/156; Washington, DC, International Monetary Fund). https://doi.org/10.5089/9781484305942.001

Mollerman, E. (2005). 'Diversity in Demographic Characteristics, Abilities and Personality Traits: Do Faultlines Affect Team Functioning?', Group Decision and Negotiation, 14(3), 173-93. https://doi.org/10.1007/s10726-005-6490-7

Muchiri, M. (2011), 'Leadership in Context: A Review and Research Agenda for Sub-Saharan Africa', Journal of Occupational and Organizational Psychology, 84(3): 440-52. https://doi.org/10.1111/j.2044-8325.2011.02018.x

Munene, J. (1995), 'The Institutional Environment and Managerial Innovations: A Qualitative Study of Selected Nigerian Firms', Journal of Occupational and Organizational Psychology, 68(4): 291-300. https://doi.org/10.1111/j.2044-8325.1995.tb00588.x

Munro, D. (1986), 'Work Motivation and Values: Problems and Possibilities in and out of Africa', Australian Journal of Psychology, 38(3): 285-96. https://doi.org/10.1080/00049538608259015

Ndiaye, S. (2017), 'The Rise of SMEs in Sub-Saharan Africa', International Development Journal, https://idjournal.co.uk/2017/05/20/africa-needs-smes/.

Nkomo, S. (2011), 'A Post-Colonial and Anti-Colonial Reading of "African" Leadership and Management in Organisation Studies: Tensions, Contradictions and Possibilities', Organisation, 18(3): 365-86. https://doi.org/10.1177/1350508411398731

Nkomo, S. \& Kriek, D. (2011), 'Leading Organisational Change in the 'New' South Africa, Journal of Occupational and Organizational Psychology, 84(3): 453-70. https://doi.org/10.1111/j.2044-8325.2011.02020.x

Nkomo, S., Zoogah, D. \& Acquaah, M. (2015), 'Why Africa Journal of Management and Why Now?', Africa Journal of Management, 1(1): 4-26. https://doi.org/10.1080/23322373.2015.994419

Oglesby, C. (1969), 'Vietnam Has Failed. The Revolution Can Only be Mauled not Defeated', Commonweal, 90.

Patterson, F. (2001), 'Developments in OOP: Emerging Issues and Future Trends', Journal of Occupational and Organizational Psychology, 74(4): 381-90. https://doi.org/10.1348/096317901167442

Pidd, M. \& Broadbent, J. (2015), 'Business and Management Studies in the 2014 Research Excellence Framework', British Journal of Management, 26: 569-81.

https://doi.org/10.1111/1467-8551.12122

Pisani, N. (2009), 'International Management Research: Investigating Its Recent Diffusion in Top Management Journals', Journal of Management, 35(3): 199-218.

https://doi.org/10.1177/0149206308321552

Pollet, T. V. \& Saxton, T. K. (2019), 'How Diverse are the Samples Used in the Journals "Evolution \& Human Behavior" and "Evolutionary Psychology", Evolutionary Psychological Science, 5: 357-68. https://doi.org/10.1007/s40806-019-00192-2

Pratt, G. \& Bonaccio, S. (2016), 'Qualitative Research in I-O Psychology: Maps, Myths and Moving Forward', Industrial and Organizational Psychology, 9(4): 693-715.

https://doi.org/10.1017/iop.2016.92 
Puplampu, B. (2010), 'Leadership as Engagement, Leadership as System Development: A Contextualised Ghanaian Study', European Business Review, 22(6): 624-51. https://doi.org/10.1108/09555341011082925

Puplampu, B. (2013), 'Employee Motivation in Africa', in T. Lituchy, B. Punnett \& B.B. Puplampu (eds) Management in Africa-Macro and Micro Perspectives (New York, Routledge).

Puplampu, B. (2016), 'Alternative Approaches to Management Research Africa: Hermeneutics, Graphic Scales and Applied Interventions', in H. Kazeroony, Y. du Plessis \& B.B. Puplampu (eds) Sustainable Management Development in Africa. Building Capabilities to Serve African Organizations (Routledge, New York), 171-87.

Puplampu, B. (2017), 'Return to Africa to Mine an African Understanding of Employee Motivation in Africa: Sankofa', Africa Journal of Management, 3(3/4): 213-35. https://doi.org/10.1080/23322373.2017.1375811

Reader, J. (1998), Africa: Biography of a Continent (New York, Vintage).

Roethlisberger, F. \& Dickson, W. (1939), Management and the Worker (Cambridge, MA, Harvard University Press).

Sayer, D. (2014), 'Five Reasons Why The REF is Not Fit For Purpose', The Guardian, 15 December.

Singh, G., Haddad, K. \& Chow, C. (2007), 'Are Articles in "Top” Management Journals Necessarily of Higher Quality?', Journal of Management Inquiry, 16: 319-31. https://doi.org/10.1177/1056492607305894

Sparrow, P. (1999), 'Editorial', Journal of Occupational and Organizational Psychology, 72(3): 261-4. https://doi.org/10.1348/096317999166653

Tadic, M., Bakker, A. B. \& Oerlemans, W. G. (2015), 'Challenge Versus Hindrance Job Demands and Well-being: A Diary Study on the Moderating Role of Job Resources', Journal of Occupational and Organizational Psychology, 88(4): 702-25. https://doi.org/10.1111/joop.12094

Tourish, D. (2019), Management Studies in Crisis: Fraud, Deception, and Meaningless Research (Cambridge, Cambridge University Press). https://doi.org/10.1017/9781108616669

Trompenaars, F. (1993), Riding the Waves of Culture: Understanding Cultural Diversity in Business (London, Economist Books).

UN Fact Sheet (n.d.), Indigenous Peoples, Indigenous Voices, Factsheet1 https://un.org/esa/socdev/unpfii/documents/5session_factsheet1.pdf [Accessed 4 June 2020].

US Bureau of Labor Statistics (2014), Occupational Outlook Handbook. (Washington, DC, US Bureau of Labor Statistics).

Weiner, B. (1986), An Attributional Theory of Motivation and Emotion (New York, Springer). https://doi.org/10.1007/978-1-4612-4948-1

West, M., Arnold, J., Corbett, M. \& Fletcher, B. (1992), 'Editorial: Advancing Our Understanding about Behaviour at Work', Journal of Occupational and Organizational Psychology, 65(1): 1-3. https://doi.org/10.1111/j.2044-8325.1992.tb00479.x

Whetten, D. (1989). 'What Constitutes a Theoretical Contribution?', Academy of Management Review, 14(4): 490-5. https://doi.org/10.2307/258554

\section{Notes on the authors}

Bill Buenar Puplampu is Professor of Organisational Behaviour, a Chartered Psychologist and Associate Fellow of the British Psychological Society. He is currently the Vice Chancellor of Central University, Ghana. He is a member of the Global University Leaders Council (Hamburg) and a Fellow of the Ghana Academy. 
His research interests are in organisational culture, corporate leadership and employee motivation.

bpuplampu@central.edu.gh

Chris Lewis, after many years in academia, is now Principal of the consultancy Aver Psychology. He was formerly Visiting Professor at Central University in Ghana. He is a Chartered Psychologist, Chartered Scientist, Associate Fellow of The British Psychological Society, and Fellow of The Royal Statistical Society. He is past Chair of the Division of Occupational Psychology of The British Psychological Society. He was the 2014 Lifetime Achievement Award Winner in Occupational Psychology (DOP/BPS). His research interests are in research methodology and psychometrics, especially in relation to geopolitical diversity issues.

chris.lewis@dial.pipex.com

To cite the article: Bill Buenar Puplampu and Chris Lewis (2021), 'Geopolitical diversity in Occupational and Organisational Psychology: shaking off historical comforts and confronting real-world challenges', Journal of the British Academy, 9(s1): 257-284.

DOI https://doi.org/10.5871/jba/009s1.257

Journal of the British Academy (ISSN 2052-7217) is published by

The British Academy, 10-11 Carlton House Terrace, London, SW1Y 5AH

www.thebritishacademy.ac.uk 